\title{
Lung Cancer pT4 TNM Finding v8
}

National Cancer Institute

\section{Source}

National Cancer Institute. Lung Cancer pT 4 TNM Finding v8. NCI Thesaurus. Code C136457.

Lung cancer with tumor measuring more than $7 \mathrm{~cm}$ or tumor of any size invading one or more of the following: diaphrag m, mediastinum, heart, great vessels, trachea, recurrent laryngeal nerve, esophagus, vertebral body, or carina; separate tumor nodule(s) in an ipsilateral lobe different from that of the primary. (from AJCC 8th Ed.) 